\title{
Electrical resistivity sensors for monitoring the water exchange in hardened concrete
}

\author{
Rubén Beltrán Cobos ${ }^{1}$, Fabiano Tavares Pinto ${ }^{1}$ and Mercedes Sánchez Moreno ${ }^{1,2, *}$ \\ 1 Department of Inorganic Chemistry, University of Córdoba (UCO), Spain; rbeltran@uco.es; ftavares@uco.es \\ 2 Institute on NanoChemistry (IUNAN), University of Córdoba (UCO), Spain; msmoreno@uco.es \\ * Correspondence: msmoreno@uco.es; Tel.: +34 957218660
}

\begin{abstract}
The development of a remote sensing system is proposed in the present study for monitoring of the electrical resistance of concrete in real time. The sensor is embedded in the concrete bulk, and the data are sent via a gateway to a computer for the data analysis. The sensibility of the sensors to the effect of the presence of a crystalline admixture has been also assessed in the study. Different cycles of drying and water penetration have been considered to assess the sensor performance in different water content conditions. Sensors have shown to capable of detecting changes in electrical resistance when humidity changes. The sensitive of the sensors to the action of waterproofing admixtures in the mortar has been also confirmed. The contribution of the temperature plays a critical role on the sensor response, and its simultaneous monitoring is recommended.
\end{abstract}

Keywords: wireless monitoring; electrical resistance sensors; humidity; crystalline admixtures; water exchange; concrete.

\section{Introduction}

Although water is needed for concrete hydration, the presence of liquid water in hardened concrete pores can be associated to the development of damage processes such as the rebar corrosion, sulphate attack or deterioration due to freeze and thaw weathering $[1,2]$. In this context, the application of waterproofing solutions for controlling the water penetration in in service conditions but maintaining the concrete performance appears as a promising alternative for improving the durability of concrete structures.

Crystalline admixtures (CA) are classified as Permeability-Reducing Admixtures able to improve the water-tightness of concrete under hydrostatic service conditions [3]. Crystalline admixtures are a family of commercial additives with hydrophilic behaviour able to react in presence of water producing water-insoluble precipitates [4].

The waterproofing efficiency of CAs has been reported by different authors [5-8] using permeability tests at the laboratory. The increase of the impermeabilization with time has been observed when hydrophilic blends are used as crystalline admixtures [5]. These tests for the assessment of the waterproofing ability associated to the additive presence are carried out at specific curing ages, and under controlled testing conditions [6]. The water penetration through the waterproofed concrete surface is measured after the test $[7,8]$. However, other interesting parameters such as the time needed for water get into the concrete or the rate of water penetration remain unknown. The best way to evaluate these other parameters is monitoring in real time the water penetration from the surface to the concrete bulk. Incorporating in the concrete a sensing system able to detect changes in the water content of the concrete appears as a highly promising technology for going deeper in the assessment of waterproofing efficiency. 
Humidity must be considered as key parameter for the successful structural health monitoring of concrete structures [9]. Several types of humidity sensors have been proposed in the literature [10] incorporating different technologies and materials. However, in general, these sensors are not specifically designed for embedding in concrete.

Different SHT digital sensors have been proposed for embedding in concrete as part of a wireless sensor network able to monitor humidity and temperature in concrete. However, the performance of this type of humidity sensors has not been proved to be as good as expected, as this type of sensors does not work on water saturated conditions, such as the curing conditions in concrete [11,12]. Although different solutions have been reported for avoiding the water saturated conditions due to the water condensation on the sensor, no one has proved to be efficient. Barroca et al. [11] propose a porous mortar shell for improving the sensor performance while Chang and Hung [12] protect the sensor with an encapsulation box of Gore-Tex incorporating a flux of air for drying the sensor.

Electrical resistivity has been proposed as indirect parameter for assessing the water content in concrete [13]. Reitermann et al. [14] used electrical resistivity as testing method for analysing the ability of crystalline admixtures to create an impermeable layer when applied as coating on the concrete surface. The waterproof performance of the coated concrete was assessed by controlling moisture conditions, and an electrical resistivity moisture meter was used for performing resistivity measurements at different defined time intervals.

Embedded sensors for the continuous monitoring of electrical resistivity have also been proposed in the literature [15-19]. The effect of influencing parameters such as the temperature has been evaluated $[15,16]$. Embedded sensors have been used for obtaining resistivity mappings on concrete samples [17]. Different miniaturized sensors have been proposed $[18,19]$. However, most of the proposed systems involve the use of a data-logger for the data acquisition and the presence of a technician for retrieving these data.

In the present work, the development of a remote sensing system is proposed for the continuous monitoring of the electrical resistance of concrete. The sensor is embedded in the concrete bulk, and the data are sent via a gateway to a computer for the data analysis. The sensibility of the sensors to effect of the presence of a crystalline admixture has been also assessed in the study.

\section{Materials and Methods}

\subsection{Specimens preparation}

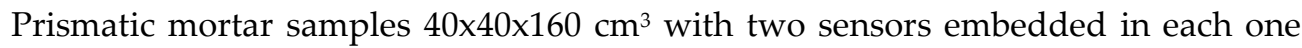
were prepared for monitoring the electrical resistance response. Two different cases were considered: a reference mortar without admixtures and a waterproofed mortar incorporating a commercial crystalline admixture $(\mathrm{ADD}+2.5 \AA)$. The mortar mix proportion is detailed in Table 1. Ordinary Portland Cement (OPC), normalized silica sand $(0-4 \mathrm{~mm})$ and tap water were used for the sample preparation. A fixed w/c ratio of 0.5 was maintained for all the cases. The recommended dosage of the crystalline admixture (CA) - was added to the mortar. The mortar mixes were prepared according to the Spanish standard EN 1961:2005. Polymeric molds were used for avoiding interference in the electric resistance measurements of the sensors. The samples for mechanical testing were casted in metal casts. 
Table 1. Mortar mix proportion of the studied samples (in $\mathrm{g} / \mathrm{mold}$ ).

\begin{tabular}{lllllc}
\hline Sample name & $\begin{array}{l}\text { OPC ce- } \\
\text { ment }\end{array}$ & $\begin{array}{l}\text { Siliceous } \\
\text { sand }\end{array}$ & Water & CA & w/c ratio \\
\hline Reference mortar & 450 & 1350 & 225 & --- & 0.5 \\
Mortar with CA & 450 & 1350 & 225 & 4 & 0.5 \\
\hline
\end{tabular}

\subsection{Fabrication of the wireless monitoring integrated system}

Sensors for monitoring the evolution of the electrical resistance in the bulk of the mortar samples were specifically designed and fabricated for the study. As schematized in Figure 1, a small PCB (Print Circuit Board) with 5 tin-plated metal points of the same size $\left(2.4 \mathrm{~mm}^{2}\right)$, separated a constant distance of $2.5 \mathrm{~mm}$, was used. The two opposite points closest to the end of the PCB were used for measuring. The design of the sensor is based on the idea of further application to assess the water penetration at different depths in the mortar bulk.

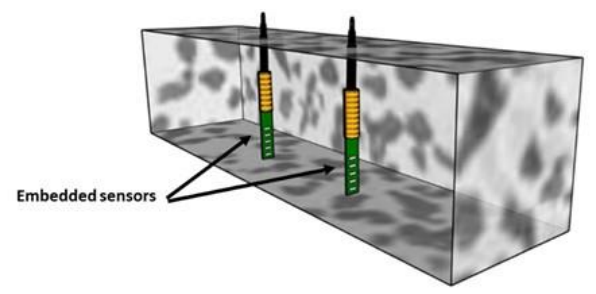

Figure 1. Scheme of the sensors embedded in the mortar samples.

The prototype was based on a development board Teensy 3.6 to read the resistivity sensor once a minute. The sensor values were registered into a native micro SD card port. To guarantee the proper work of the equipment, a Bluetooth module was installed to send the data in real time to a mobile device as a serial terminal.

For the need to read several sensors with the equipment in continuous mode a 32nodes home-made multiplexer module was developed. It was used 8 ADG511 as monolithic CMOS ICs containing four independently selectable analogical switches each, driven by four 74HC595 as high speed CMOS 8-bit shift register.

The measurements were carried out determining the charge/discharge time of a capacitor with known capacitance when an AC voltage is applied. The charge/discharge frequency is directly related to the electrical resistance of the mortar through a previous calibration procedure.

\subsection{Monitoring of the water exchange in real-time}

To assess the waterproofing ability of the crystalline admixture, the response of the electrical resistance sensors embedded in the mortar samples was monitored in different situations of water exchange. The mortar samples were submitted to different water exchange scenarios:

a) Drying process: two different conditions were considered for drying the mortar samples, a slower process in the laboratory environment and a more accelerated process in oven at a constant temperature of $40^{\circ} \mathrm{C}$.

b) Water penetration: a capillary absorption test was carried out for the penetration of water through the opposed surface to the surface where the sensors were embedded. 
The sensor response was continuously monitored during the exposure of the mortar samples to the different exposure conditions, and the evolution of the electrical resistance values was indirectly related to the water exchange through the concrete pores.

\section{Results and discussion}

\subsection{Sensor response in drying conditions}

The response of the sensor when the reference mortar sample was exposed to a drying process can be observed in Figure 2. Two different drying conditions were considered for assessing the behavior of the control sample: a slow process at the laboratory environment and an accelerated process in an oven at $40^{\circ} \mathrm{C}$.

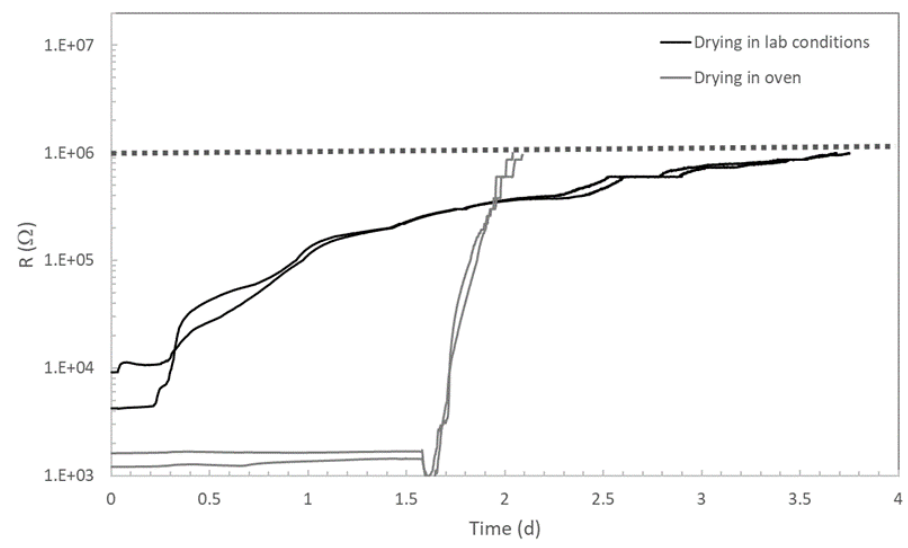

Figure 2. Evolution of the electrical resistance of reference mortar in different drying conditions (laboratory environment and oven at $40^{\circ} \mathrm{C}$. (Scale $y$-axis in logarithmic view for better presentation of the results).

As can be observed from Figure 2, the drying conditions play a critical role on the sensor response. In both cases a delay in the response of the sensor is registered. In the laboratory conditions, after about 4 hours, a progressive increase in the resistance value is recorded with the drying time. However, when the dry is carried out under accelerated conditions, the changes are detected by the sensor only after more than 36 hours, and a sharp response in the resistance values is observed after the delay.

The influence of the high temperature in the oven should be influencing the electric resistance value as expected from Arrehenius Law [20]. In fact, just before starting the sharp increase of the resistance values, a decrease is observed during a short period of time. Lower values of the electrical resistance are not expected due to the drying processes of the mortar. In this sense, it can be concluded that the electrochemical sensor for monitoring the electrical resistance of the mortar during a drying process is not appropriate when there is a significant temperature change between the humid and dry conditions as the sensor response is not only related to the physic-chemical changes in the cementitious matrix but mainly with the influence of the temperature.

The maximum value of the electrical resistance, non-measurable by the sensor, $1 \mathrm{M} \Omega$, has been stablished as criteria for considering complete drying of the sample. As expected, this condition is reached significantly faster when an accelerated drying of the mortar in an oven is considered. In 2 days, the sample reached this maximum value when the drying process occurs at $40^{\circ} \mathrm{C}$ in the oven, but when the mortar is exposed to the drying process at the laboratory atmosphere is not registered until almost 4 days drying.

The decrease of electric resistance values with the temperature increase has been assessed heating a saturated $\mathrm{Ca}(\mathrm{OH})_{2}$ solution from $40^{\circ} \mathrm{C}$ to $90^{\circ} \mathrm{C}$ with the sensor immersed. In Figure 3 the evolution of electric resistance as function of the temperature has been represented. 


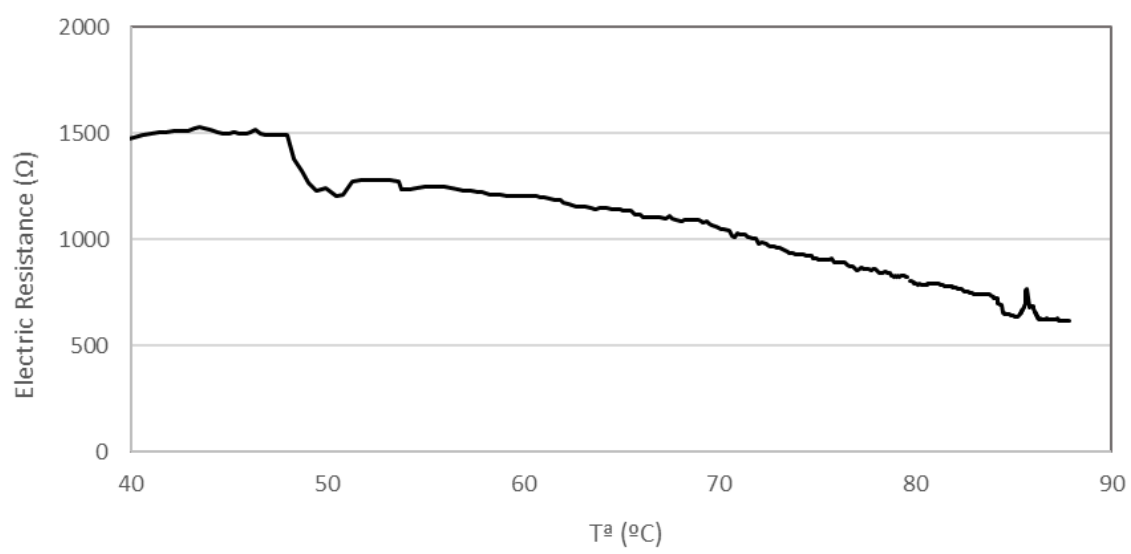

Figure 3. Response of a sensor immersed in a saturated $\mathrm{Ca}(\mathrm{OH})_{2}$ solution during a heating process from $40^{\circ} \mathrm{C}$ to $90^{\circ} \mathrm{C}$.

\subsection{Sensor response in humid conditions}

After the drying process in laboratory conditions, the monitored sample was exposed to water penetration by capillary absorption from the surface. The mortar sample was immersed to a water level of $5 \mathrm{~mm}$ from the surface opposed to the sensor location. The electric resistance was monitored with the exposure time, as shown in Figure 4.

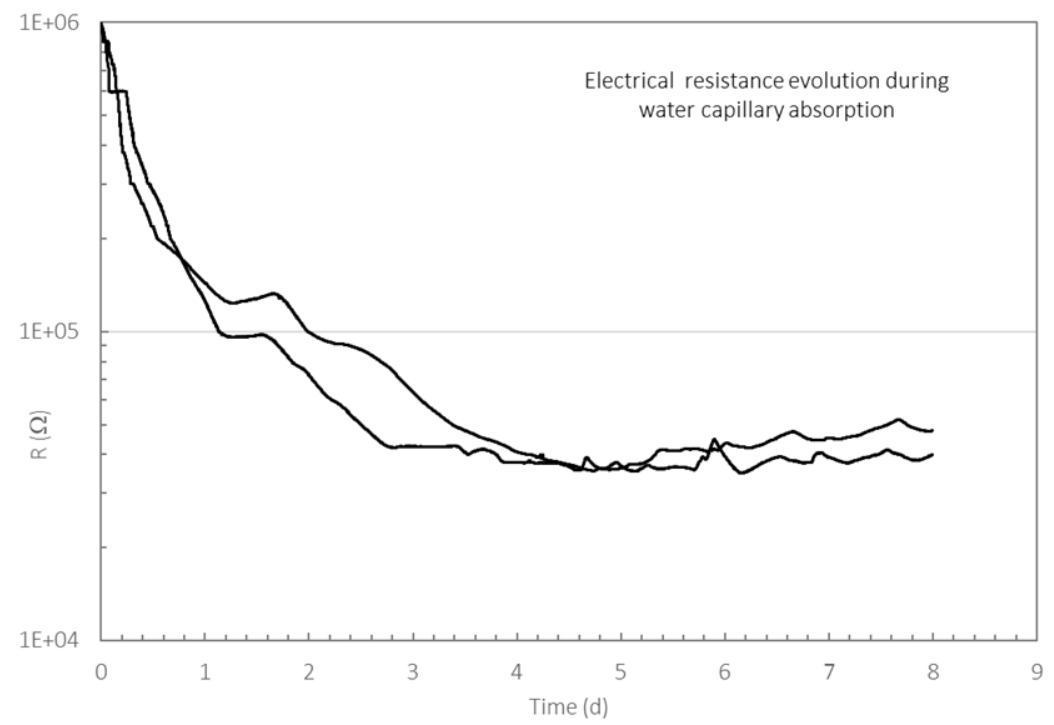

Figure 4. Electrical resistance evolution during a water capillary absorption test.

As can be observed from Figure 4, the electrical resistance value suffered a continuous decrease just from the moment of the contact with water. The decrease of the resistance is significantly faster during the first day of contact with water, probably due to the influence of the temperature until an equilibrium was reached. After this sharp decrease, a more moderated decrease can be observed until 3-4 days of exposure. The water arrival to the sensors is expected to be taking place in this period, until reaching a saturated condition, associated to the almost constant values registered after this second period (from $3-4$ days of exposure). Both sensors stabilized, after about 4 days of water exposure, at about $40 \mathrm{k} \Omega$ of electrical resistance, a little bit higher than the initial values registered just after the curing in saturated conditions (see Figure 3).

The initial response of the sensor when the mortar sample is expose to the penetration of water by capillary absorption significantly depends on the starting condition, if the sample was dried in oven, in an accelerated way, or it was dried in the laboratory environment. In Figure 5 it can be observed that electric resistance values are very low from 
the first measurement $(<2 \mathrm{k} \Omega)$, being the evolution of this first contact with water faster than the monitoring rate of the system. During the first day the electrical resistance decreases; however, after this time an unexpected slight increase in the resistance values is registered. A significant influence of the high temperature during the first period can be deduced from the low values of resistance. The equilibration of the temperatures along time would decrease this influence, and thus, after half-day, the electrical resistance tends to increase, to higher values like in the case of water capillary absorption test after drying in the laboratory environment.

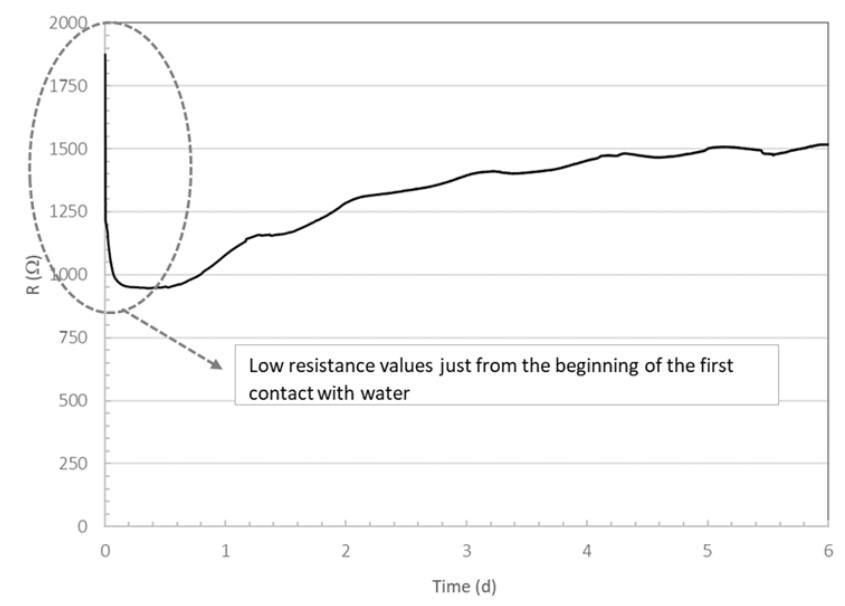

Figure 5. Evolution of electrical resistance values during water capillary absorption test after an accelerated drying at $40^{\circ} \mathrm{C}$ in oven.

\subsection{Sensibility of the sensor to the presence of waterproofing crystalline admixtures}

The response of the sensor embedded in a mortar containing crystalline admixtures has been compared with the sensor embedded in a reference mortar with admixtures during a drying process at the laboratory environment, as can be observed from Figure 6.

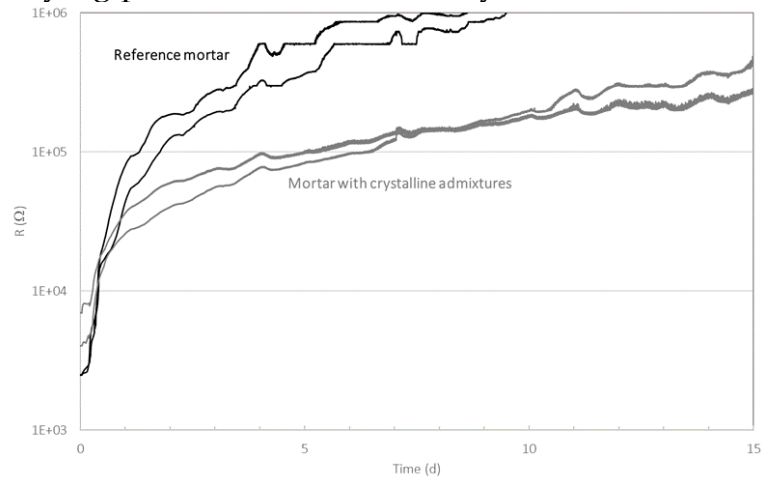

Figure 6. Electrical resistance evolution during drying in the laboratory environment of both a reference mortar and a mortar with crystalline admixtures (two sensors per case of study).

A slower increase of electrical resistance values with time is observed in the sensors embedded in the mortar containing crystalline admixtures. Furthermore, lower values of resistance are maintained during the whole time of testing. While the sensors embedded in the reference mortar almost reach the maximum resistance values after about 5 days drying, in the case of the sensor embedded in the mortar with crystalline admixtures, even after 10 days drying, the resistance values are below this maximum (about $300 \mathrm{k} \Omega$ ).

These lower resistance values registered by the sensors when embedded in the mortar containing crystalline additives would indicate a slower loss of water from the mortar sample, that would be related to the mechanism of the crystalline admixture added, that retains water to promote further hydration reactions forming new products that fill the 
pores [1]. In this sense, the sensors embedded in the mortar can indirectly identify the action of the crystalline admixture through the evolution of the electrical resistance values.

In the case of drying under accelerated conditions in an oven at $40^{\circ} \mathrm{C}$ this behaviour is also observed, as represented in Figure 7.

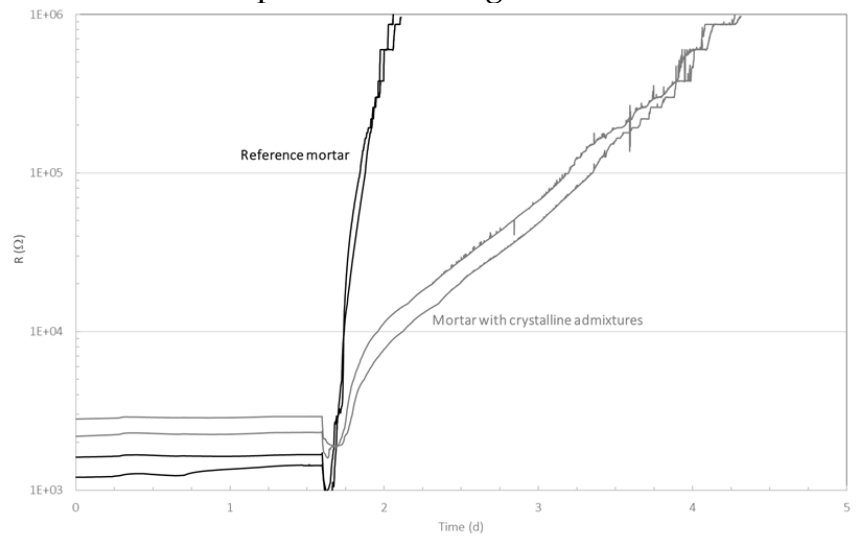

Figure 7. Electrical resistance evolution during an accelerated drying process in an oven at $40^{\circ} \mathrm{C}$ (reference mortar and mortar with crystalline admixtures, two sensors per case of study).

The effect of the high temperature on the response of the sensors is observed in all the embedded sensors, similarly to the previous section describing the effect of the type of drying on the sensor response (Figure 2). However, once the temperature is equilibrated and the sensor response is due to the mortar bulk properties, the resistance increase in the mortar containing the crystalline admixtures is significantly slower than the increase registered in the reference mortar, confirming the sensibility of the sensor to the presence of the crystalline admixture. Thus, in similar way than in the case of drying in the laboratory, the embedded sensors allow identifying the effect of the presence of the crystalline admixture in the mortar mix.

\section{Conclusions}

It can be stated that the sensors are capable of detecting changes in electrical resistance under different drying and wetting conditions, which in turn indicates the internal presence of moisture in the mortar.

Resistivity sensors have shown to be also sensitive to the action of waterproofing admixtures in the mortar. Different electrical resistance response is registered for the mortar containing the crystalline admixtures that for the reference one. The delay in reaching the maximum resistance values in comparison to the reference mortar allows identifying the action of the crystalline additive, being able to differentiate between specimens with different permeability.

The temperature monitoring is required together with the resistance monitoring to identify the contribution of this parameter in the resistance values. A abrupt temperature change for a drying process is not an appropriate condition to assess the performance of the electrical resistance sensors.

Author Contributions: “Conceptualization, F. Tavares and M. Sánchez; methodology, R. Beltrán and F. Tavares; software, F. Tavares; validation, R. Beltrán, F. Tavares and M. Sánchez; formal analysis, R. Beltrán, F. Tavares and M. Sánchez; investigation, R. Beltrán, F. Tavares and M. Sánchez.; resources, M. Sánchez; writing - original draft preparation, R. Beltrán; writing - review and editing, M. Sánchez and F. Tavares; visualization, M. Sánchez; supervision, M. Sánchez and F. Tavares; project administration, M. Sánchez; funding acquisition, M. Sánchez. All authors have read and agreed to the published version of the manuscript."

Funding: This research was funded by the Spanish Government, grant number RYC-2016-21422. Authors also acknowledge Krystalline Technology enterprise for supplying the crystalline materials for the study, and their recommendations for the application of the admixtures. 
Acknowledgments: Authors also acknowledge Krystalline Technology enterprise for supplying the crystalline materials for the study, and their recommendations for the application of the admixtures.

Conflicts of Interest: The authors declare no conflict of interest.

\section{References}

1. Strangfeld, C.; Kruschwitz, S. Monitoring of the absolute water content in porous materials based on embedded humidity sensors. Constr Build Mater 2018, 177, 511-521. https://doi.org/10.1016/j.conbuildmat.2018.05.044.

2. Azarsa, P.; Grupta, R. Electrical resistivity of concrete for durability evaluation: a review. Adv Mater Sci Eng 2017, 8453095, 30 pages. https://doi.org/10.1155/2017/8453095.

3. ACI Committee 212. Chapter 15: Permeability-reducing admixtures. In Report on Chemical Admixtures for Concrete. American Concrete Institute, Farmington Hills, 2016; pp. 43-48. ISBN: 978-1-942727-80-4.

4. De Belie, N.; Gruyaert, E.; Al-Tabbaa, A.; Antonaci, P.; Baera, C.; Bajare, D.; Darquennes, a.; Davies, R.; Ferrara, L.; Jefferson, A.; et al. A Review of Self-Healing Concrete for Damage Management of Structures. Adv Mater Interfaces 2018, 5, 1800074, 28 pages. https://doi.org/10.1002/admi.201800074.

5. García Calvo, J.L.; Sánchez Moreno, M.; Carballosa, P.; Pedrosa, F.; Tavares, F. Improvement of the concrete permeability by using hydrophilic blended additive. Materials 2019, 12, 2384, 12 pages. http://dx.doi.org/10.3390/ma12152384.

6. Guzlena, S.; Sakale, G. Self-healing concrete with crystalline admixture - a review. IOP Conf. Ser. Mater. Sci. Eng. 2019, 660, 012057, 7 pages. https://doi.org/10.1088/1757-899X/660/1/012057.

7. Pazderka, J.; Hájková, E. Crystalline admixtures and their effect on selected properties of concrete. Acta Polytech. 2016, 56, 306311. https://doi.org/10.14311/AP.2016.56.0306.

8. Nataadmadja, A.D.; Runtuwene, J.A.P. Analysis of concrete permeability with additional waterproofing admixture. IOP Conf. Ser. Earth Environ. Sci. 2018, 195, 012002. 9 pages. https://doi.org/10.1088/1755-1315/195/1/012002.

9. Taheri, S. A review on five key sensors for monitoring of concrete structures. Constr Build Mater 2019, $204,492-509$. https://doi.org/10.1016/j.conbuildmat.2019.01.172.

10. Farahani, H.; Wagiran, R.; Hamidon, M.N. Humidity sensors principle, mechanism, and fabrication technologies: a comprehensive review. Sensors 2014, 14, 7881-7939. https://doi.org/10.3390/s140507881.

11. Barroca, N.; Borges, L.M., Velez, F.J.; Monteiro, F.; et. al. Wireless sensor networks for temperature and humidity monitoring within concrete structures. Constr Build Mater 2013, 40, 1156-1166. https://doi.org/10.1016/j.conbuildmat.2012.11.087.

12. Chang, C.Y.; Hung, S.S. Implementing RFIC and sensor technology to measure temperature and humidity inside concrete structures. Constr Build Mater 2012, 26, 628-637. https://doi.org/10.1016/j.conbuildmat.2011.06.066.

13. Nguyen, A.Q.; Klysz, G.; Deby, F.; Balaysaac, J.P. Evaluation of water content gradient using a new configu ration of linear array four-point probe for electrical resistivity measurement. Cem Concr Compos 2017, 83, 308-322. https://doi.org/10.1016/j.cemconcomp.2017.07.020.

14. Reiterman, P.; Pazderka, J. Crystalline coating and its influence on the water transport in concrete. Adv. Civ. Eng. 2016, 2513514, 8 pages. https://doi.org/10.1155/2016/2513514.

15. Villagrán Zaccardi, Y.A.; Fullea García, J.; Huélamo, P.; Di Maio, A.A. Influence of temperature and humidity on Portland cement mortar resistivity monitored with inner sensors. Mater. Corros. 2009, 60, 294-299. https://doi.org/10.1002/maco.200805075

16. Andrade, C.; Zuloaga, P.; Martínez, I.; Castillo, A.; Briz, S. Effect of temperature on corrosion parameters and apparent activation energy measured by embedded sensors in pilot container in El Cabril repository. Corros. Eng. Sci. Techn. 2011, 46, 182-189. https://doi.org/10.1179/1743278211Y.0000000007.

17. Priou, J.; Lecieux, Y.; Chevreuil, M.; Gaillard, V.; Lupi, C.; Leduc, D.; Roziére, E.; Guyard, R.; Schoefs, F. In situ DC electrical resistivity mapping performed in a reinforced concrete wharf using embedded sensors. Constr Build Mater 2019, 211, 244-260. https://doi.org/10.1016/j.conbuildmat.2019.03.152.

18. Lee, J.; Harada, K.; Kwon, Y. Development of water content sensor composed of small copper electrodes for use during fire resistance tests of concrete and cement mortar elements. Fire Mater 2018, 42, 88-98. https://doi.org/10.1002/fam.2460.

19. Corva, D.M.; Hossini, S.S.; Collins, F.; Adams, S.D.; et al. Miniature resistance measurement device for structural health monitoring of reinforced concrete infrastructure. Sensors 2020, 20, 4313, 18 pages. https://doi.org/10.3390/s20154313.

20. Rangelov, M.; Nassiri, S. Evaluation of methods to correct the effect of temperature on electrical conductivity of mortar. Adv. Civ. Eng. 2018, 9327528, 9 pages. https://doi.org/10.1155/2018/9327528. 